\title{
Supplemental Effect of Lactobacillus Plantarum on the Growth Performance, Nutrient Digestibility, Gas Emission, Excreta Microbiota, and Meat Quality in Broilers
}

-Author(s)

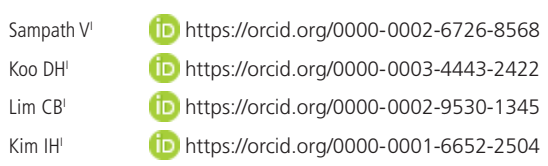

Department of Animal Resource and Science, Dankook University, No. 29 Anseodong,

Cheonan, Choongnam - 330-714, South Korea.

\section{Mail Address}

Corresponding author e-mail address In Ho Kim

Department of Animal Resource \& Science, Dankook University, No. 29 Anseodong, Cheonan, Choongnam, 330-714, South Korea.

Phone: +82-41-550-3652

Email: inhokim@dankook.ac.kr

\section{- Keywords}

Lactobacillus plantarum, growth performance, excreta microbiota, broiler

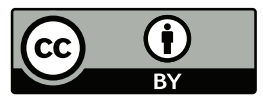

Submitted: 09/February/2021 Approved: 06/August/2021

\section{ABSTRACT}

The goal of this study was to investigate the effects of Lactobacillus plantarum (L. plantarum) supplementation on the growth performance, nutrient digestibility, gas emission, excreta microbiota, and meat quality in broilers. A total of two hundred eighty-eight, one-day-old Ross-308 chicks (mixed sex) were randomly allocated to one of two treatments with eight replicated cages (18 chicks per cage). For a period of 35 days, control treatment chicks were fed commercial corn-soybean mealbased (CON) mash form diet, whereas, LP (Lactobacillus plantarum) - chicks were fed CON with $0.10 \%$ L. plantarum supplement. The dietary inclusion of $0.10 \% \mathrm{~L}$. Plantarum supplementation has a trend to increase the body weight gain (BWG) of broilers at day $7(p=0.079)$ and significantly increased at day $21(p=0.011)$ and the overall trial period ( $p=0.037$ ) compared to the CON diet. In addition, $0.10 \% \mathrm{~L}$. plantarum supplementation to basal diet significantly decreased $\mathrm{H}_{2} \mathrm{~S}$ $(p=0.046)$ concentration. Also, it has significantly increased the excreta Lactobacillus population $(p=0.041)$ and reduced the $E$. coli count $(p=0.054)$ compared to the CON diet. However, throughout the trial there were no significant differences observed on nutrient digestibility of dry matter, nitrogen, and gross energy, as well as meat quality traits in broilers, fed $0.10 \%$ L. plantarum diet. In summary, the inclusion of $L$. plantarum supplementation has a beneficial effect on growth performance, excreta microbiota, and gas emission. From this, we conclude that $0.10 \%$ of $L$. plantarum could be a potential feed additive to enhance poultry production.

\section{INTRODUCTION}

Poultry production has grown rapidly and becomes a competitive industry all over the world. The growth of poultry production has a profound impact on the demand for nutritious feed ingredients. Although feed addition plays an important role in livestock diet, the availability of lowcost and high-quality feeds is even more important if poultry production continues to grow quickly and to meet consumer demand for animal protein. On a large-scale rearing farm, chickens are exposed to a variety of diseases that leads to stressful situations and severe economic losses. To tackle this situation, the use of antibiotic growth promoters (AGP) has been increased. However, in the recent years, the haphazard use of AGP has raised concerns due to anti-microbial resistance. In response to this apparent threat, South Korean government has banned the use of AGP in livestock feed since 2011 (Sampath et al., 2021a). Thus, manufactures and nutritionists were urged to seek alternative feed additives that could eventually stimulate the growth ability of broilers. One of the eco-friendly approaches to growth promotion involves the use of probiotics, which have been used in the livestock industry for decades (Smith, 2014). 


\section{Supplemental Effect of Lactobacillus Plantarum on the Growth Performance, Nutrient Digestibility, Gas Emission, Excreta Microbiota, and Meat Quality in Broilers}

(Basal diet); LP, (CON $+0.10 \%$ probiotic). A nutritious diet during the grower (d 1-21) and finisher (d22-35) stages were formulated to meet the requirements of NRC 1994 (Table 1). After the initial weighing of the basal diet, probiotic was incorporated in the feed at the prescribed level $(0.10 \%)$ excluding the control group and provided to broilers for 35 days at the same time (14:00-15:00) whilst, clean water and feed was provided until the end of the experiment. Broilers were weighed at days 7,21 , and 35 . The amount of diet consumed and remaining (each cage) were recorded daily to evaluate the feed intake (FI). On day 35, body weight (BW), feed intake ( $\mathrm{FI})$, feed conversion ratio $(F C R)$, and the mortality rate were recorded. Chromic oxide $(0.3 \%)$ as an indigestible marker was added to broiler diet on day 28 and provided for about one week until the end of the experiment to measure the nutrient digestibility. The representative feed samples were collected using the sterilized plastic bags from each treatment group right after mixing the marker.

Table 1 - Feed composition of broiler (as fed-basis).

\begin{tabular}{|c|c|c|}
\hline Item & Grower & Finisher \\
\hline \multicolumn{3}{|l|}{ Ingredients (\%) } \\
\hline Corn & 48.55 & 55.35 \\
\hline Soybean meal & 30.12 & 26.54 \\
\hline Corn gluten meal & 13.00 & 10.00 \\
\hline Wheat bran & 3.00 & 3.00 \\
\hline Soy oil & 1.75 & 1.50 \\
\hline $\mathrm{TCP}$ & 1.85 & 1.85 \\
\hline Limestone & 0.91 & 0.92 \\
\hline Salt & 0.36 & 0.36 \\
\hline Methionine (99\%) & 0.19 & 0.19 \\
\hline Lysine & 0.07 & 0.09 \\
\hline Mineral mix & 0.10 & 0.10 \\
\hline Vitamin mix² & 0.10 & 0.10 \\
\hline Total & 100.00 & 100.00 \\
\hline \multicolumn{3}{|l|}{ Calculated value } \\
\hline Crude protein, \% & 21.07 & 19.40 \\
\hline $\mathrm{Ca}, \%$ & 1.08 & 1.07 \\
\hline $\mathrm{P}, \%$ & 0.82 & 0.79 \\
\hline Available P, \% & 0.53 & 0.52 \\
\hline Lys, \% & 1.15 & 1.06 \\
\hline Met, \% & 0.52 & 0.50 \\
\hline $\mathrm{ME}, \mathrm{kcal} / \mathrm{kg}$ & 3200 & 3200 \\
\hline FAT, \% & 4.54 & 4.34 \\
\hline Fiber, \% & 3.46 & 3.27 \\
\hline Ash, \% & 6.52 & 6.24 \\
\hline
\end{tabular}

${ }^{1}$ Provided per $\mathrm{kg}$ of complete diet: $37.5 \mathrm{mg} \mathrm{Zn}\left(\mathrm{as} \mathrm{ZnSO}_{4}\right) ; 37.5 \mathrm{mg} \mathrm{Mn} \mathrm{(as} \mathrm{MnO}_{2}$ ); $37.5 \mathrm{mg} \mathrm{Fe}\left(\mathrm{as} \mathrm{FeSO}_{4} \cdot 7 \mathrm{H}_{2} \mathrm{O}\right.$ ); $3.75 \mathrm{mg} \mathrm{Cu}\left(\mathrm{as} \mathrm{CuSO}_{4} \cdot 5 \mathrm{H}_{2} \mathrm{O}\right.$ ); $0.83 \mathrm{mg} \mathrm{I}$ (as KI); and 0.23 $\mathrm{mg} \mathrm{Se}\left(\mathrm{as} \mathrm{Na}_{2} \mathrm{SeO}_{3} \cdot 5 \mathrm{H}_{2} \mathrm{O}\right)$.

2Provided per kg of complete diet: $15,000 \mathrm{IU}$ of vitamin A, 3,750 IU of vitamin $\mathrm{D}_{3}, 37.5$ IU of vitamin $E_{1} 2.55 \mathrm{mg}$ of vitamin $\mathrm{K}_{3}, 3 \mathrm{mg}$ of Thiamin, $7.5 \mathrm{mg}$ of Rivoflavin, $4.5 \mathrm{mg}$ of vitamin $B_{6}, 24 \mathrm{ug}$ of vitamin $B_{12}, 51 \mathrm{mg}$ of Niacin, $1.5 \mathrm{mg}$ of Folic acid, $0.2 \mathrm{mg}$ of Biotin and $13.5 \mathrm{mg}$ of Ca-Pantothenate. 
On day 35, fresh excreta samples were randomly (32 birds/treatment) (4 birds/ cage) collected using a stainless steel collection tray. The excreta samples were pooled and transported to the laboratory, and stored at $-20^{\circ} \mathrm{C}$ to examine the nutrient digestibility of dry matter (DM), nitrogen ( $N)$, and energy (E). Prior to analysis, freeze-dried samples were placed in a digital hot air-drying convection oven at $105^{\circ} \mathrm{C}$ for 24 hours. The samples were then taken out from the oven, milled, and sieved using a $1 \mathrm{~mm}$ screen sieve. $\mathrm{DM}$ and $\mathrm{N}$ procedures were carried out according to the method of AOAC (2005). GE was analyzed using Parr 6400 oxygen bomb calorimeter (Parr Instrument Co., Moline, IL, USA), whereas N was analyzed using Tecator $^{\mathrm{TM}}$ Kjeltec8400 analyzer (Hoeganaes, Sweden). The chromium absorption was identified using UV1201 spectrophotometry. The total tract digestibility was calculated using: ATTD $(\%)=100-[(\mathrm{NF} / \mathrm{ND}) \times(\mathrm{CrD} /$ $(\mathrm{rF})] \times 100]$. Hence NF, ND, CrD and $\mathrm{CrF}$ were referred as nutrient concentration in the excreta sample, nutrient concentration in the diet, chromium concentration in the diet, and chromium concentration in the excreta sample, respectively.

On day 35, excreta samples were collected (32 birds/ treatment) (4 birds/ cage) using a stainless steel tray, homogenized and stored in sterilized microtubes at 16:00 (pm), placed in an ice container, and immediately taken to the laboratory. $1 \mathrm{gm}$ of fresh excreta sample was taken and diluted in $9 \mathrm{ml}$ of $1 \%$ peptone solution and mixed using vortex mixer. The microbial analysis was done according to the procedure of Sampath et al. (2021b). Around 17:00 (pm) fresh excreta samples (approximately $300 \mathrm{~g}$ ) were randomly collected from (32 birds/treatment) (4 birds/ cage) the pooled well, and stored in an airtight plastic box of $2.6 \mathrm{~L}$ with a slight hole on one side, fasten tightly with adhesive tape and fermented at $25^{\circ} \mathrm{C}$ for 7 days. On the 8th day, a $100 \mathrm{ml}$ sample was taken away from the headspace $(2 \mathrm{~cm})$ for the air circulation, and the box was resealed. To know the crust formation on the surface the sample container was manually shaken for about 30 seconds. Finally, $\mathrm{CO}_{2}$, acetic acid, $\mathrm{H}_{2} \mathrm{~S}, \mathrm{NH}_{3}$, and methyl mercaptans were measured using the scopes of 5.0 to 100.0 ppm (No. 3La, detector tube; Gastec Corp. Kanagawa, Japan) and 2.0 to 20.0 ppm (4LK, detector tube; Gastec Corp).

Broilers (32 birds/treatment) (4 birds/ cage) were sacrificed by cervical dislocation. The abdominal fat, liver, gizzard, spleen, bursa of fabricius, and breast muscle were carefully removed by the experts. The relative organs were weighed individually and estimated as mass BW. The respective samples were taken to the laboratory, and the breast meat was separated for meat quality analysis. The color parameters such as redness, lightness, and yellowness standards of each sample (surface) were measured at 3 locations with a portable Konica Minolta CR-400 chroma meter (Osaka, Japan). The $\mathrm{pH}$, water holding capacity (WHC), drip loss, and cooking loss were calculated following the methods of Sampath et al. (2021b).

\section{Statistical analysis}

All the data were analyzed as a completely randomized block design using the GLM procedure of SAS (version 9.2; SAS Institute, Cary, NC). When significant differences were identified among treatment means, they were separated using T- test. The cages were considered as experimental units. Variability in the data was expressed as the standard error of means $\mathrm{P}<0.05$ was considered to be statistically significant.

\section{RESULTS AND DISCUSSION}

L. plantarum was widely used as probiotics and exerts a beneficial effect on the host by modulating their intestinal tract (Cebeci et al., 2003). The growth performance of broilers fed L. plantarum supplement is presented in Table 2. The dietary inclusion of $0.10 \%$ probiotics supplementation tends to increase $(p=0.079)$ the BWG on the $7^{\text {th }}$ day and significant increase on the $21^{\text {st }}$ day $(p=0.011)$ and the overall trial period ( $p=0.037$ ) compared to the CON diet. Our result agreed with Peng et al., (2016) who observed a higher ADG in broiler fed L. plantarum supplementation. Similarly, Kalavathy et al. (2003) reported that dietary Lactobacillus had improved the body weight gain of broilers. On the other hand, Ramarao et al. (2004) reported that the body weight gain of broilers was not influenced by dietary probiotic supplementation, which opposed to the findings of our experiment. Although Peng and co-authors report that the dietary inclusion of $L$. plantarum supplementation has improved the feed conversion ratio of broilers, in this study the broilers fed $0.10 \%$ L. plantarum supplement failed to improve FCR and the feed intake throughout the experimental period. To support our results, Siadati et al. (2017) reported that Lactobacillus supplement failed to influence the feed intake of Japanese quails. The reason for the improvements in body weight gain of broilers fed $0.10 \%$ L. plantarum in the current study was probably due to the increased population of beneficial intestinal bacteria and reduction of 
the pathogenic bacteria residents. The provision of nutrient diet with particular energy and amino acids is more important for the efficient feed utilization (Yi et al., 2015). Hence, we assume the lack of feed intake and FCR results might be due to the energy or protein content in the experimental diet or due to the environmental factors.

Table 2-The effect of dietary L. plantarum supplementation on growth performance of broilers ${ }^{1}$

\begin{tabular}{lcccc}
\hline Items & CON & LP & SEM $^{2}$ & $p$-value \\
\hline d 1 to 7 & & & & \\
\hline BWG, g & 136 & 140 & 2.04 & 0.079 \\
Fl, g & 163 & 168 & 5.27 & 0.371 \\
FCR & 1.201 & 1.198 & 0.04 & 0.955 \\
\hline d 7 to 21 & & & & \\
\hline BWG, g & $630^{b}$ & $662^{\text {a }}$ & 10.86 & 0.011 \\
Fl, g & 871 & 895 & 22.6 & 0.318 \\
FCR & 1.383 & 1.351 & 0.02 & 0.115 \\
\hline d 21 to 35 & & & & \\
\hline BWG, g & 906 & 934 & 34.19 & 0.416 \\
Fl, g & 1957 & 1989 & 42.43 & 0.456 \\
FCR & 2.172 & 2.138 & 0.08 & 0.706 \\
\hline Overall & & & & \\
\hline BWG, g & $1671^{b}$ & $1736^{\mathrm{a}}$ & 28.34 & 0.037 \\
Fl, g & 2991 & 3052 & 52.84 & 0.273 \\
FCR & 1.792 & 1.759 & 0.04 & 0.444 \\
Mortality & 4.86 & 6.25 & 2.54 & 0.594 \\
\hline
\end{tabular}

'Abbreviation: CON (Basal diet); LP, CON $+0.10 \%$ probiotics.

${ }^{2}$ Standard error of means.

a,b Means in the same row with different superscripts differ $(p<0.05)$.

A healthy intestinal tract is essential for livestock animals to absorb the nutrients and to provide a barrier against pathogenic bacteria (Hong et al., 2005). Earlier studies have reported that Lactobacilli could exert a positive effect on the gastrointestinal tract as they increase feed consumption and nutrient absorption from the intestines (Awad et al., 2009). Once, Lactobacillus supplements enter into the intestinal tract it may convert carbohydrates into lactic acid, reduce $\mathrm{pH}$ of the intestinal and increase the activities of trypsin, amylase, lipase, and total proteolytic enzymes to increase the length of villi and decrease the depth of the recess, which is beneficial for the digestion and absorption of food nutrients by the animals (Högberg and Lindberg, 2006). In the current study, broilers fed $0.10 \%$ L. plantarum supplementation failed to affect DM, N, and E (Table 3). Similarly, Chen et al. (2006) also noted that finishing pigs fed Bacillus-based probiotic supplement has no significant differences on digestibility of DM and N. Moreover, Shon et al. (2005) indicated that growing pigs fed $0.2 \%$ Lactobacillus complex $(1 \times 109$ CFU $/ \mathrm{kg})$ diet did not affect the ATTD of DM and N. In contradiction, Liu et al. (2018) stated that probiotic (B. subtilis and S. cerevisiae) supplementation improved nutrient digestibility of growing pigs, while the similar effect was addressed by Jørgensen et al. (2016). We assume that the variation in these results may be due to different probiotic strains or due to the difference in animals. The lack of nutrient digestibility in broilers fed $0.10 \%$ L. plantarum is unknown, thus further studies are needed to clarify the effect of $L$. plantarum on broilers nutrient digestibility by altering the supplementation level of experimental diet composition.

Table 3 - Effect L. plantarum supplementation on nutrient digestibility of broilers ${ }^{1}$

\begin{tabular}{lcccc}
\hline Items & CON & LP & SEM $^{2}$ & $p$-value \\
\hline Finish & & & & \\
Dry matter & 71.98 & 73.50 & 0.15 & 1.072 \\
Nitrogen & 69.94 & 70.64 & 0.51 & 1.051 \\
Gross energy & 70.95 & 72.12 & 0.36 & 1.224 \\
\hline
\end{tabular}

'Abbreviation: CON (Basal diet); LP, CON $+0.10 \%$ probiotics.

${ }^{2}$ Standard error of means.

The harmful substances produced in excreta may lead to various health issues to the farmworkers as well as animals (Mcmichael et al., 2007). In this study, broiler fed $0.10 \%$ probiotic supplementation has significantly decreased $\mathrm{H}_{2} \mathrm{~S}(p=0.046)$ emission, whereas it fails to affect other parameters such as $\mathrm{NH}_{3}$, total mercaptans, CO2, and acetic acid (Table 4). Yet, our result was partially agreed with Zhao et al. (2015) who observed a decreased $\mathrm{H}_{2} \mathrm{~S}, \mathrm{NH}_{3}$ and total mercaptans emission in pigs fed $L$. plantarum and $L$. reuteri complex diet. Similarly, Han et al. (2005) reported that $0.2 \%$ of complex probiotic supplement which contains Lactobacillus had significantly decreased $\mathrm{NH}_{3}$ emission in growing pigs. Previously, Chu et al. (2011) reported that the inclusion of probiotics in livestock feed has effectively decreased the level of ammonia, fecal $\mathrm{pH}$, volatile organic matter and helps to get rid of the toxic odor. Apart from this, Escherichia coli is one of the most important bacteria for the cause of diarrhea

Table 4 - Effect L. plantarum supplementation on excreta gas emission in broilers ${ }^{1}$

\begin{tabular}{lcccc}
\hline Items, ppm & CON & LP & SEM $^{2}$ & $p$-value \\
\hline Finish & & & & \\
$\mathrm{NH}_{3}$ & 14.7 & 12.5 & 3.08 & 0.507 \\
$\mathrm{H}_{2} \mathrm{~S}$ & 1.8 & $0.8^{\mathrm{ab}}$ & 3.89 & 0.046 \\
Methyl mercaptans & 9.0 & 6.6 & 2.58 & 0.528 \\
$\mathrm{CO}_{2}$ & 1725 & 1425 & 340.9 & 0.412 \\
Acetic acid & 4.7 & 2.7 & 1.34 & 0.192 \\
\hline
\end{tabular}

'Abbreviation: CON (Basal diet); LP, CON $+0.10 \%$ probiotics.

${ }^{2}$ Standard error of means.

$a, b$ Means in the same row with different superscripts differ $(p>0.05)$. 


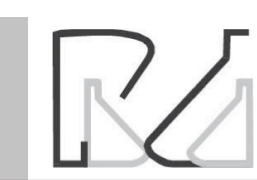

in animals. Previous studies have shown that $L$. plantarum diet could inhibit the growth of pathogens by competing with the limiting nutrients to regulate the composition of intestinal microflora and to form a biological barrier (Tian et al., 2010). The present study reveals that the inclusion of $0.10 \% \mathrm{~L}$. plantarum in broiler diet has significantly increased the Lactobacillus population $(p=0.041)$ and reduced the $E$. coli counts $(p=0.054)$ and no effect on Salmonella counts (Table 5). To support our results, Nguyen et al. (2019) stated that probiotics mixture $(B$. coagulans, $B$. licheniformis, $B$. subtilis, and C. butyricum) has significantly improved fecal Lactobacillus populations and decreased E. coli counts in weaning pigs. One probable reason for the increased BWG and decreased concentration of $\mathrm{H}_{2} \mathrm{~S}$ in the excreta emission may be due to the presence of good bacteria (Lactobacillus) in the gut of broilers.

Table 5 - Effect L. plantarum supplementation on excreta microbiota of broilers ${ }^{1}$

\begin{tabular}{lcccc}
\hline Items, $\log _{10} \mathrm{cfu} / \mathrm{g}$ & CON & LP & SEM $^{2}$ & $p$-value \\
\hline Finish & & & & \\
Lactobacillus & 9.13 & $9.35^{\mathrm{ab}}$ & 0.05 & 0.041 \\
E. coli & 6.37 & $6.16^{\mathrm{ab}}$ & 0.05 & 0.054 \\
Salmonella & 4.38 & 4.28 & 0.121 & 0.417 \\
\hline
\end{tabular}

'Abbreviation: CON (Basal diet); LP, CON $+0.10 \%$ probiotics.

${ }^{2}$ Standard error of means.

a,b Means in the same row with different superscripts differ $(p<0.05)$.

The determination of poultry meat quality become a complicated concept since it depends on
Supplemental Effect of Lactobacillus Plantarum on the Growth Performance, Nutrient Digestibility, Gas Emission, Excreta Microbiota, and Meat Quality in Broilers

consumer preferences (Ishamri Ismail and Seon Tea Joo, 2017). Such meat quality traits were not affected by the experimental diet. Though, Kim et al. (2008) demonstrated that the inclusion of $0.1 \%$ complex probiotics which includes $L$. plantarum $\left(1.0 \times 10^{8}\right.$ $\mathrm{cfu} / \mathrm{g}$ ) in the diet of finishing pig has reduced the drip loss and increased meat color, however, in this study the meat color and drip loss in broilers fed $0.10 \% L$. plantarum were not affected (Table 6). To date, the effect of supplementing $0.10 \% \mathrm{~L}$. plantarum in broiler diets, on the meat quality is not well elucidated. Thus, enhance the comparisons could not be made with other studies. Further studies are needed with different doses of $L$. plantarum to evaluate their effects on the production traits of broilers.

\section{CONCLUSION}

Our data revealed that the administration of an $L$. plantarum strain could improve the BWG, reduced $\mathrm{H}_{2} \mathrm{~S}$ concentrations in the excreta thereby contributing to reduce the release of harmful gas emissions from poultry farms. In addition, the administration of $0.10 \%$ L. plantarum plays a vital role in the modulation of the gut microbiota as confirmed by the increase in excreta of Lactobacillus population and decrease in E. coli counts. From the obtained results, we concluded that $0.10 \%$ of L. Plantarum could be used as a potential feed additive to enhance the poultry production.

Table 6 - Effect L. plantarium supplementation on meat quality and organ weight of broilers ${ }^{1}$

\begin{tabular}{|c|c|c|c|c|}
\hline Items & $\mathrm{CON}$ & LP & SEM $^{2}$ & $p$-value \\
\hline \multicolumn{5}{|c|}{ Relative organ weight, \% } \\
\hline Breast muscle & 18.04 & 18.14 & 1.09 & 0.925 \\
\hline Liver & 2.52 & 2.61 & 0.16 & 0.621 \\
\hline Spleen & 0.14 & 0.17 & 0.02 & 0.378 \\
\hline Abdominal fat & 0.60 & 1.26 & 0.41 & 0.166 \\
\hline Bursa of Fabricius & 0.16 & 0.13 & 0.03 & 0.292 \\
\hline Gizzard & 1.92 & 1.72 & 0.11 & 0.309 \\
\hline \multicolumn{5}{|l|}{ Breast muscle color } \\
\hline Lightness $\left(L^{*}\right)$ & 57.52 & 57.83 & 1.51 & 0.845 \\
\hline Redness $\left(a^{*}\right)$ & 11.76 & 11.55 & 0.78 & 0.799 \\
\hline Yellowness(b*) & 12.19 & 13.60 & 2.1 & 0.531 \\
\hline $\mathrm{pH}$ value & 5.72 & 5.62 & 0.05 & 0.095 \\
\hline Cooking loss, \% & 21.02 & 19.98 & 2.89 & 0.731 \\
\hline WHC, \% & 54.01 & 54.63 & 5.19 & 0.908 \\
\hline \multicolumn{5}{|l|}{ Drip loss, \% } \\
\hline d 1 & 3.97 & 3.04 & 0.75 & 0.261 \\
\hline d 3 & 6.77 & 6.19 & 0.82 & 0.507 \\
\hline d 5 & 12.66 & 14.31 & 0.92 & 0.124 \\
\hline d 7 & 17.64 & 16.83 & 0.59 & 0.218 \\
\hline
\end{tabular}

${ }^{1}$ Abbreviation: CON (Basal diet); LP, CON + 0.10\% probiotics.

${ }^{2}$ Standard error of means. 


\section{CONFLICTS OF INTEREST}

No potential conflict of interest relevant to this article was reported.

\section{ACKNOWLEDGMENT}

The Department of Animal Science \& Resource was supported through the Research-Focused Department Promotion Project as a part of the University Innovation Support Program for Dankook University in 2021 and the authors gratefully acknowledge the Center for BioMedical Engineering Core-Facility at Dankook University for providing critical reagents and equipment.

\section{REFERENCES}

Abudabos AM, Al-Batshan HA, Murshed MA. Effects of Prebiotics and probiotics on the performance and bacterial colonization of broiler chickens. South African Journal of Animal Science 2015;45(4):419.

AOAC - Association of Official Analytical Chemists. Official methods of analysis. $18^{\text {th }}$ ed Arlington; 2005.

Awad W, Ghareeb K, Abdel-Raheem S, Bo"hm J. Effects of dietary inclusion of probiotic and symbiotic on growth performance, organ weights, and intestinal histomorphology of broiler chickens. Poultry Science 2009;88(1):49-56.

Cebeci A, Candan G. Properties of potential probiotic lactobacillus plantarum strains. Food Microbiol 2003;20:511-518.

Chen YJ, Min BJ, Cho JH, Kwon OS, Son KS, Kim HJ, et al. Effects of dietary Bacillus-based probiotic on growth performance, nutrients digestibility, blood characteristics and fecal noxious gas content in finishing pigs. Asian-Australasian Journal of Animal Sciences 2006;19:587-592.

Chu GM, Lee SJ, Jeong HS, Lee SS. Efficacy of probiotics from anaerobic microflora with prebiotics on growth performance and noxious gas emission in growing pigs. Animal Science Journal 2011;82:282-290.

Gao PF, Hou QC, Kwok LY, Huo DX, Feng SZ, Zhang HP. Effect of feeding Lactobacillus plantarum P-8 on the faecal microbiota of the broiler chickens exposed to lincomycin. Science Bulletin 2017;62:105-13.

Han YK, Shin HT. Effects of antibiotics, copper sulfate and probiotics supplementation on performance and ammonia emission from slurry in growing pigs. Journal of Animal Science and Technology 2005;47:537546.

Högberg A, Lindberg JE. The effect of level and type of cereal nonstarch polysaccharides on the performance, nutrient utilization and gut environment of pigs around weaning. Animal Feed Science and Techology 2006;127:200-219419.

Hong HA, Duc LH, Cutting SM. The use of bacterial spore formers as probiotics. FEMS Microbiology Reviews 2005;29:813-835.

Ismail I, Joo ST. Poultry meat quality in relation to muscle growth and muscle fiber characteristics. Korean Journal of Food Science of Animal 2017;37(6):873-883

Jørgensen JN, Laguna JS, Millán C, Casabuena O, Gracia MI. Effects of a Bacillus-based probiotic and dietary energy content on the performance and nutrient digestibility of wean to finish pigs. Animal Feed Science and Technology 2016;221:54-61.
Kalavathy R, Abdullahi N, Jalaludin S, Ho YW. Effects of Lactobacillus cultures on growth performance, abdominal fat deposition, serum lipids and weight of organs of broiler chickens. British Poultry Science 2003;44;139-144.

Kanmani P, Staish kumar R, Yuvaraj N, Paari KA, Pattukumar V, Arul V. Probiotics and its functionally valuable products-a review. Critical Reviews in Food Science and Nutrition 2003;53:641-58.

Kim KS, Lim JC, Shin MS, Choi YI, Lee SC, Cho SK. Effect of dietary combined probiotics (Any-Lac $®$ ) supplementation contained with Phaffia rhodozyma on the growth performances and meat quality of pigs. Journal of Animal Science and Technology 2008;50:657-666.

Liu W, Devi S, Park J, Kim I. Effects of complex probiotic supplementation in growing pig diets with and without palm kernel expellers on growth performance, nutrient digestibility, blood parameters, fecal microbial shedding and noxious gas emission. Animal Science Journal 2018;89:552-560.

Loh TC, Choe DW, Foo HL, Sazili AQ, Bejo MH. Effects of feeding different postbiotic metabolite combinations produced by Lactobacillus plantarum strains on egg quality and production performance, faecal parameters and plasma cholesterol in laying hens. BMC Veterinary Research 2014;10:149.

Mcmichael AJ, Powles JW, Butler CD, Uauy R. Food, livestock production, energy, climate change, and health. Lancet 2007;370:1253-1263.

Nguyen DH, Nyachotib CM, Kim IH. Evaluation of effect of probiotics mixture supplementation on growth performance, nutrient digestibility, faecal bacterial enumeration, and noxious gas emission in weaning pigs. Italian Journal of Animal Science 2019;18:466-473.

NRC. Nutrient requirements of poultry. $9^{\text {th }}$ ed. Washington: National Academy Press; 1994.

Peng Q, Zeng XF, Zhu JL, Wang S, Liu XT, Hou CL, et al. Effects of dietary Lactobacillus plantarum B1 on growth performance, intestinal microbiota, and short chain fatty acid profiles in broiler chickens. Poultry |Science 2016;95(4):893-900.

Ramarao S, Reddy M, Raju M, Panda A. Growth, nutrient utilization and immune competence in broiler chicken fed probiotic, gut acidifier and antibacterial compounds. Indian Journal of Poultry Science 2004;39(2):125-130.

Sampath $\mathrm{V}$, Byoung DH Sumaiya K, Kim IH. Effect of low nutrient density diet with probiotic mixture (B. subtilis ms1, B. licheniformis SF5-1, and $S$. cerevisiae) supplementation on performance of weaner pigs. Journal of Animal Physiology and Animal Nutrition 2021a;1-8.

Sampath $\mathrm{V}$, Han K, IH Kim. Influence of yeast hydrolysate supplement on growth performance, nutrient digestibility, microflora, gas emission, blood profile, and meat quality in broilers. Journal of Animal Science and Technology 2021b;63(3):563-574

Shen X, Yi D, Ni X, Zeng D, Jing B, Lei M, et al. Effects of Lactobacillus plantarum on production performance, immune characteristics, antioxidant status, and intestinal microflora of bursin-immunized broilers. Canadian Journal of Microbiology 2013;60:193-202.

Shon KS, Hong JW, Kwon OS, Min BJ, Lee WB, Kim IH, et al. Effects of lactobacillus reuteri-based direct-fed microbial supplementation for growing-finishing pigs. Asian-Australasian Journal of Animal Sciences 2005; 18:370-374

Siadati SA, Ebrahimnezhad Y, Salehi Jouzani GH, Shayegh J. Evaluation of probiotic potential of some native lactobacillus strains on the growth performance and serum biochemical parameters of japanese quails (Coturnix coturnix japonica) during rearing period. Brazilian Journal of Poultry Science 2017;19:399-408. 
Smith JM. A review of avian probiotics. Journal of Avian Medicine and Surgery 2014;28,87-94.

Sureshkumar S, Jung SK, Kim D, Oh KB, Yang H, Lee HC, et al. Administration of L. salivarius expressing $3 D 8 \mathrm{scFv}$ as a feed additive improved the growth performance, immune homeostasis, and gut microbiota of chickens. Animal Science Journal 2020;91:e13399.

Tian H, Luo XG, Han Z, Hao R, Wang N, Jiang $Y$, et al. Identification and Characterization of Lactobacillus plantarum TH1. Proceedings of the 3rd International Conference on Future BioMedical Information Engineering; 2010 Dec 25; Hong Kong: Wuhan Institute of Technology; 2010. p.31-37.
Upadhaya S, Devi SM, Lee BI, Kim I. Poteintials of probiotics RX7 and C14 strains as an alternative to antibiotics in challenged weaning pigs. Journal of Animal Science 2016;94(Suppl 2):81.

Yi G, Yuan J, Bi H, Yan W, Yang N, Qu L. In-depth duodenal transcriptome survey in chickens with divergent feed efficiency using RNA-Seq. PLoS One 2015;10:0136765.

Zhao PY, Kim IH. Effect of direct-fed microbial on growth performance, nutrient digestibility, fecal noxious gas emission, fecal microbial flora and diarrhea score in weanling pigs. Animal Feed Science and Technology 2015;200:86-92. 
